\title{
PLASMA-RELATED GRAPHENE ETCHING: A MINI-REVIEW
}

\section{PHUONG VIET PHAM}

SKKU Advanced Institute of Nano Technology (SAINT)

Sungkyunkwan University (SKKU)

Suwon, Gyeonggi-do 440-746

Korea

Center for Multidimensional Carbon Materials

Institute for Basic Science

44919, Ulsan

Korea

e-mail: pvphuong85@ibs.re.kr

\begin{abstract}
Graphene has achieved an amazing interest from the science community through the world in term of multidisciplinary fields of nanotechnology owing to its outstanding mechanical, thermal, and physical characteristics. The plasmarelated etching of chemical vapor deposition (CVD) grown-graphene and graphene oxide (GO) utilizing different methods related to chemistry, physics, nanotechnology, and engineering are emerging as the "hot issue" for achieving the thinner graphene layer and cleaner surface in order to improve their electronics and optoelectronics in high performance device fabrication. The resided impurities and the high roughness surface due to the nature of graphene materials induced the deteriorating in its performance. Removing the impurities by surface cleaning or plasma-related graphene etching regarding layer-by-layer thinning method as the top-down lithography. In particular, the plasma-related graphene etching which is no inducing any damage for graphene lattice while maintaining the $\pi$-bonding of its, which affects conductivity will be attracting study and highly demand. This mini review will briefly address
\end{abstract}

Keywords and phrases: plasma-related graphene, ion beam, neutral beam, etching.

Received March 23, 2018; Revised May 1, 2018

(C) 2018 Scientific Advances Publishers 
the recent advances of etching technology based on emerging plasma strategies. From here, it could be used to apply similarly for the etching on other nanomaterials.

\section{Introduction}

By the mechanical graphite exfoliation utilizing the scotch tape in 2004 [1, 2], an ultrathin graphene layer has discovered and emerged as the most promising nano-sized material with the amazing electronic properties [1-17]. Unfortunately, the conductive graphene with gapless characteristics limited its novel physical and chemical properties. Therefore, the modification of graphene by using various strategies related to chemistry, physics, nanotechnology, and engineering for layerby-layer removal or contaminant removal is desirable for highly performance applications (Figure 1). To do this, the etching technology shows the great ability and gets the interests of the scientists and researchers in academy and industry through the world [18-27].

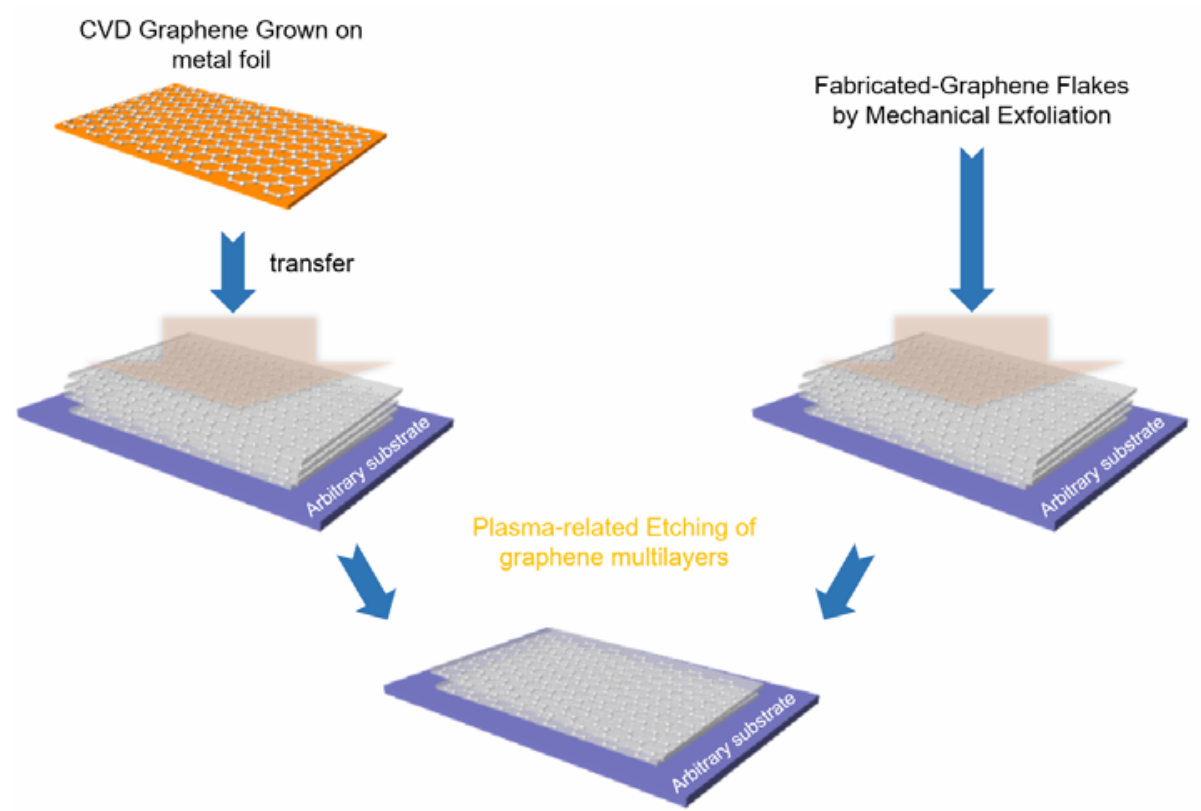

Figure 1. Schematic of plasma-related etching of graphene multilayers by chemistry, physic, nanotechnology, and engineering for tuning their electronics. 
Some novel methods have found out including (i) plasma (the inductively coupled plasma (ICP), neutral beam assisted atomic layer etching (ALET), ion beam ICP, the reactive ion etching (RIE)) [18-25], (ii) the chemical vapor deposition (CVD) [26], or (iii) thermally activated Fe nanoparticles [27]. Plasma has been used to etch fine features in Si integrated circuits in the last four decades [18]. Among the many breakthroughs that were required to make this all possible, plasma etching plays an important role for the silicon $\left(\mathrm{Si}, \mathrm{SiO}_{2}\right)$ and nonsilicon (metal)-based devices. In this editorial, I would like to present the role and the progress of the etching processes on graphene using different innovation methods, in addition, the related applications are also briefly addressed.

Foremost, the plasma etching showed the superior advantages, for instance, easily to scaleup as well as manipulation and mass production. By using the $\mathrm{O}_{2}$ plasma, the graphene multilayers were etched well on various substrates such as $\mathrm{SiO}_{2}$ [19, 21], or on $\mathrm{SiC}$ [20]. In 2014, Al-Mumen et al. reported a singular sheet etching from bilayer graphene using $\mathrm{O}_{2}$ using the grounded electrode ICP and RIE systems regarding the different plasma directions (vertical and horizontal plasma etchings) (Figure 2(a)) [19]. However, this method introduced the few defects on both, but the defects occurred much less if treated by the ICP compared than the RIE due to the higher energy damage from the RIE. The Raman data also provided the proof through the disorder characteristics based on the $I_{D} / I_{G}$ ratio which are 0.94 and 1.18 of when using the RIE and ICP, respectively [19]. Treating on another substrate, SiC, the water droplet contact angle data changed from $92.7^{\circ}$ (multilayer), 91.9 (bilayer), $92.5^{\circ}$ (single layer) down to $70^{\circ}$ when one layer etched away at the conditions of $10 \mathrm{~W}$ and 2 min of epitaxial graphene (Figure 2(b)) [20]. In another report, by nanosphere lithography using low-power $\mathrm{O}_{2}$ plasma etching, Liu et al. showed the ordering of etched graphene nanoribbons (GNRs) on $\mathrm{SiO}_{2}$ was well-formed with different shapes including branches, chains, connected rings, and circular rings (Figure 2(c)) [21]. 

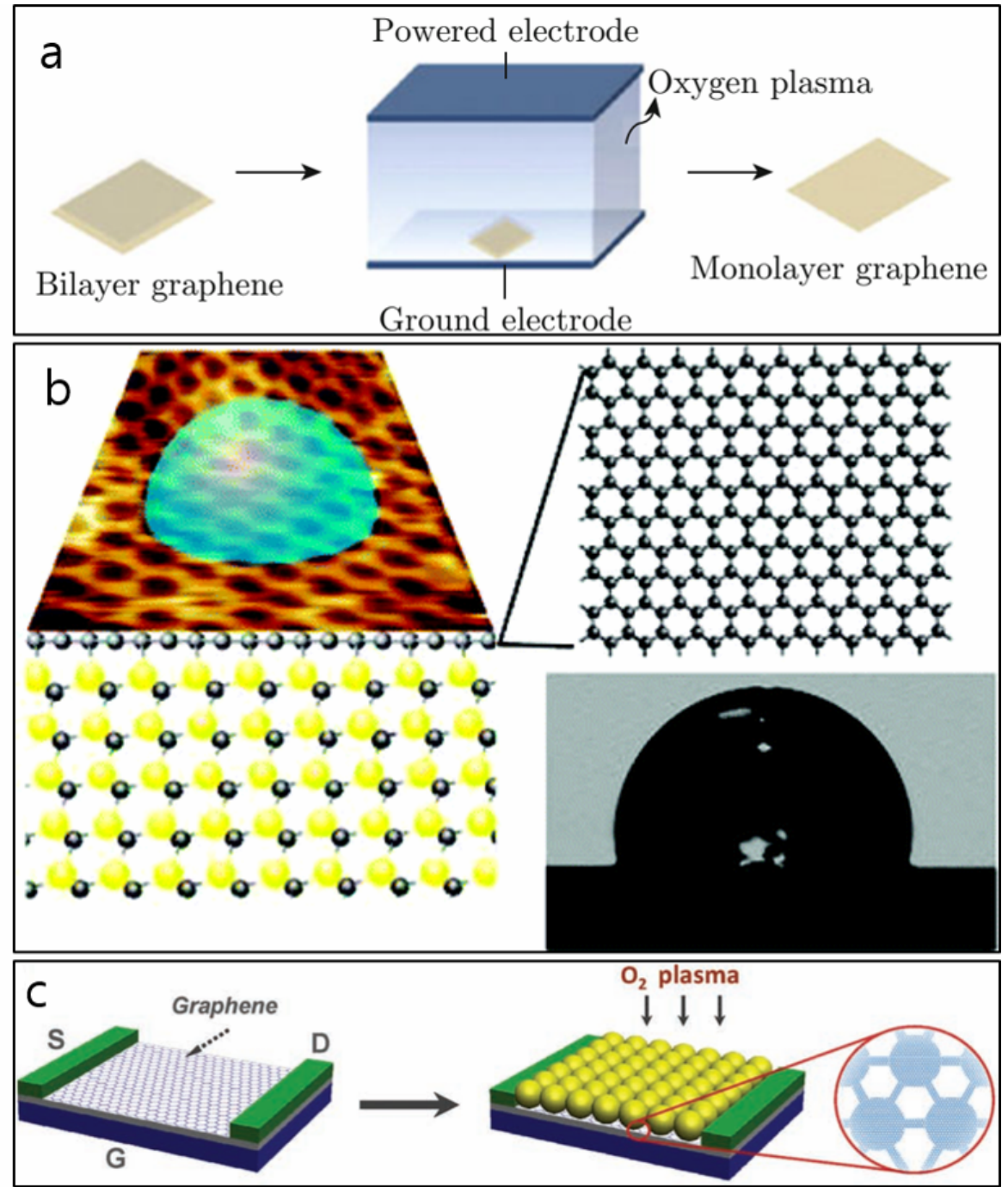

Figure 2. (a) The schematic of the graphene etching process by $\mathrm{O}_{2}$ plasma. (b) The schematic of epitaxial graphene on $\mathrm{SiC}$ after etching, the contact angle was reduced from $90^{\circ}$ to $69^{\circ}$. (c) On-chip device based on oxygen-etched nanosphere graphene; (a) is reproduced with permission from [19], copyright 2014, Springer. (b) is reproduced with permission from [20], copyright 2010, American Chemical Society. (c) is reproduced with permission from [21], copyright 2011, Wiley-VCH Verlag GmbH \& Co. KGaA, Weinheim. 
Another method in combination of plasma treatment and postannealing for layer-by-layer etching, Yang et al. utilized the $\mathrm{N}_{2}$ plasma and post-annealing ( $\mathrm{Ar} / \mathrm{O}_{2}$ mixture in $900^{\circ} \mathrm{C}$ ). As the result, this dry etch method thinned the layer-by-layer successfully from the intrinsic multilayer graphene (Figure 3(a)) [22].

In a recent innovative etching method was showed by Lim et al. [23] and Kim et al. [24], Lim et al. utilized a neutral beam assisted ALET for a two-step process of $\mathrm{O}_{2}$ radical absorption and desorption Ar neutral beam irradiation (Figure 3(b)). Consequently, the multilayer graphene was etched layer-by-layer. Although, this plasma etching method is much better than the previous report [19-22], however, the defects still occur slightly on the graphene as the D peak of the showed Raman spectra [23]. Therefore, in the most recent report in 2017, Kim et al. innovated by inserting the double mesh grid between the plasma source and the substrate holder in plasma system (Figure 3(c)) [24]. By this strategy, the damage on graphene surface did not occur during a new two-step plasma etching process using the $\mathrm{O}_{2}$ radical chemical absorption and desorption Ar physical ion beam irradiation in ICP system with the controlled plasma energy at lowering $(11.2 \mathrm{eV})[24]$. 

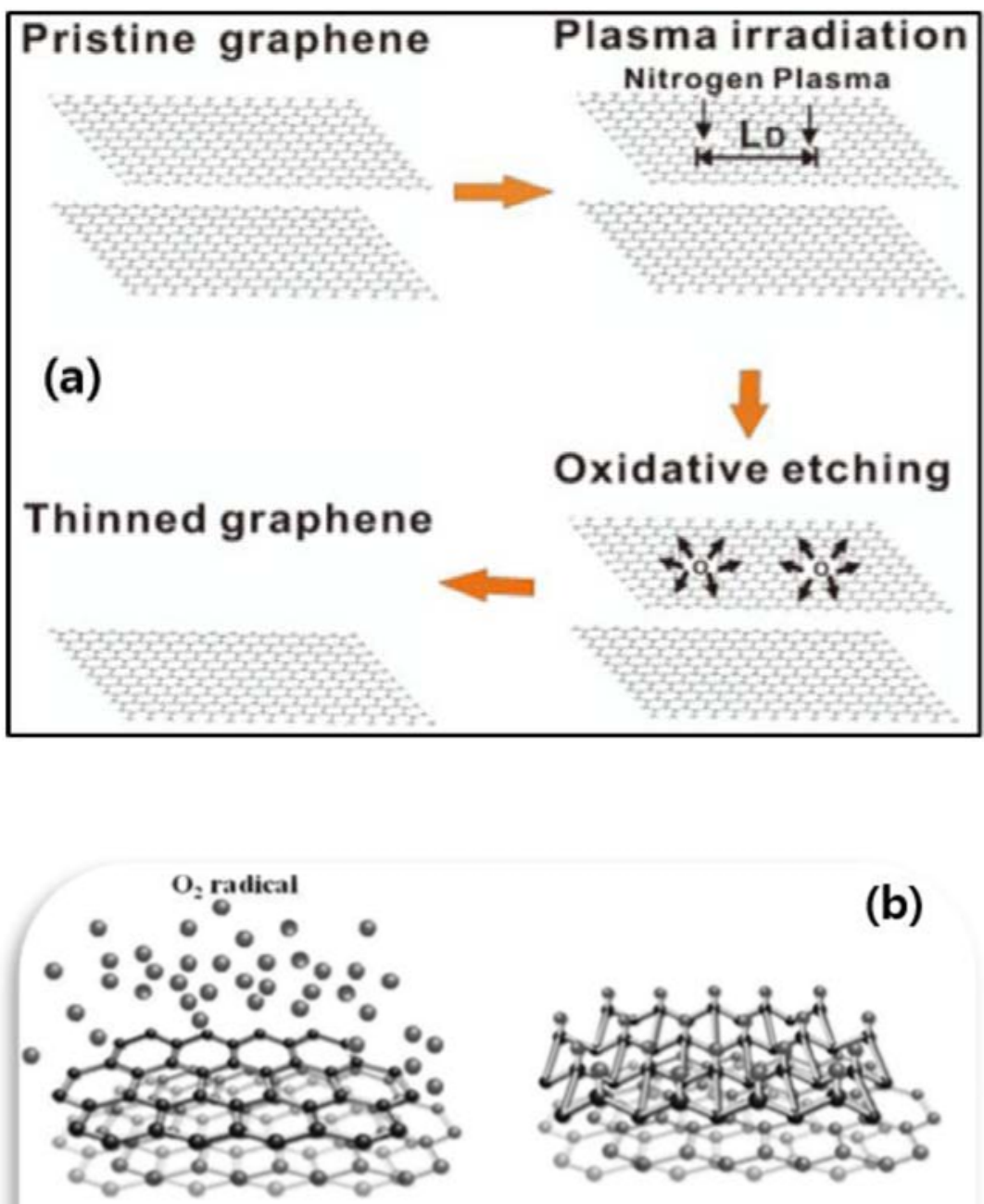

(b)
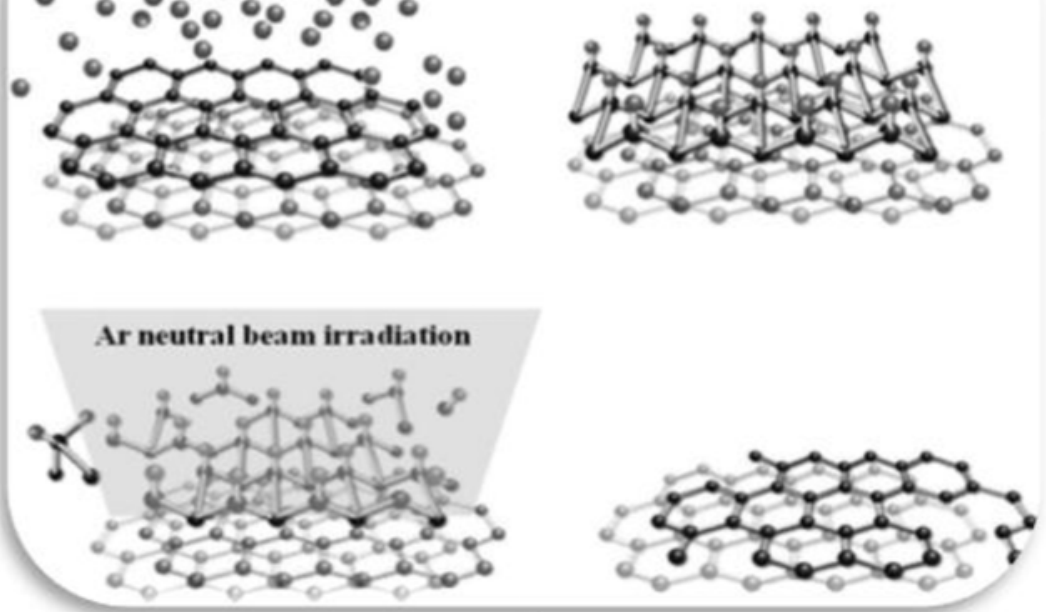


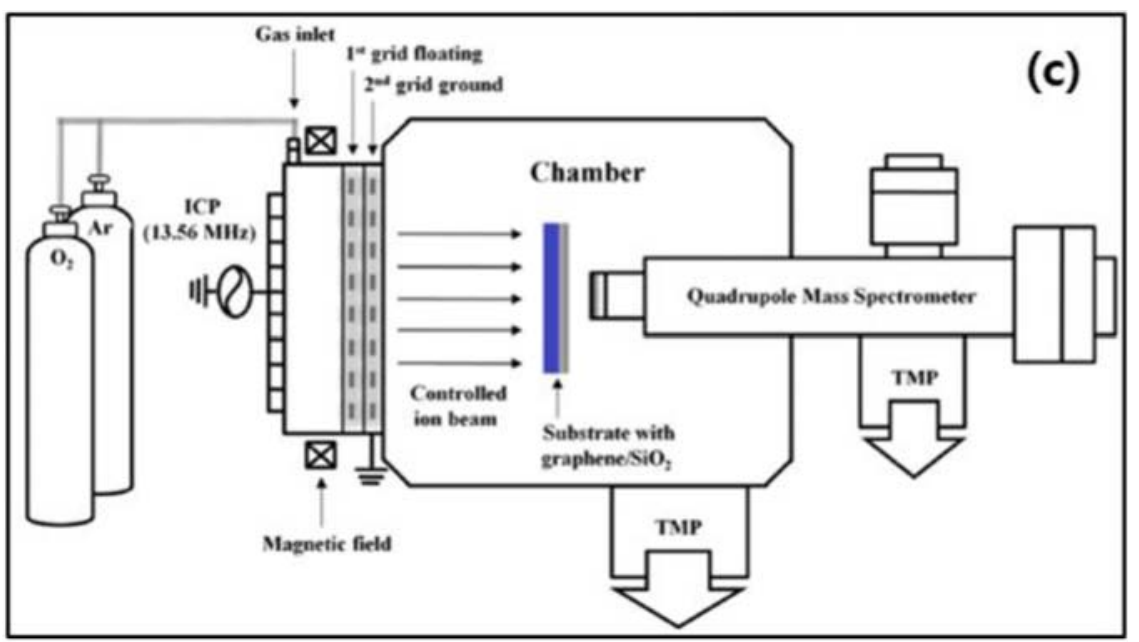

Figure 3. (a) Schematic of one-layer removal etching process by plasma irradiation ( $\mathrm{N}_{2}$ gas) and oxidative etching (annealing in $\mathrm{Ar}$ and $\mathrm{Ar} / \mathrm{O}_{2}$ ). (b) Schematic of atomic layer etching (ALET) of graphene by $\mathrm{O}_{2}$ radical absorption and desorption Ar neutral beam irradiation. (c) Schematic of a two-grid ICP-type ion beam system for graphene etching by $\mathrm{O}_{2}$ chemical absorption and physical desorption low-energy Ar ion beam. (a) is reproduced with permission from [22], copyright 2011, IOP Publishing. (b) is reproduced with permission from [23], copyright 2012, Elsevier. (c) is reproduced with permission from [24], copyright 2017, Nature Publishing Group.

In addition, there are still strategies in many different reports on the etch treating of graphene surface such as plasma etching by $\mathrm{Ar} / \mathrm{H}_{2}$ mixture in RIE (Figure 4(a)) [25], or Helium (He) ion beam lithography etching (Figure 4(b), (c)) [26], or low energy He plasma etching (Figure 5(a)-(d)) [27]. But the demonstrated results showed high defects with high D bank in Raman spectra [25]. As compared to the existing methodologies developed for etching above [26, 27], the etching method in Kim et al. [24] revealed the most superior to date due to the free-damage and perfect layer-by-layer etching on graphene surface during the plasma etching from this innovative system. 

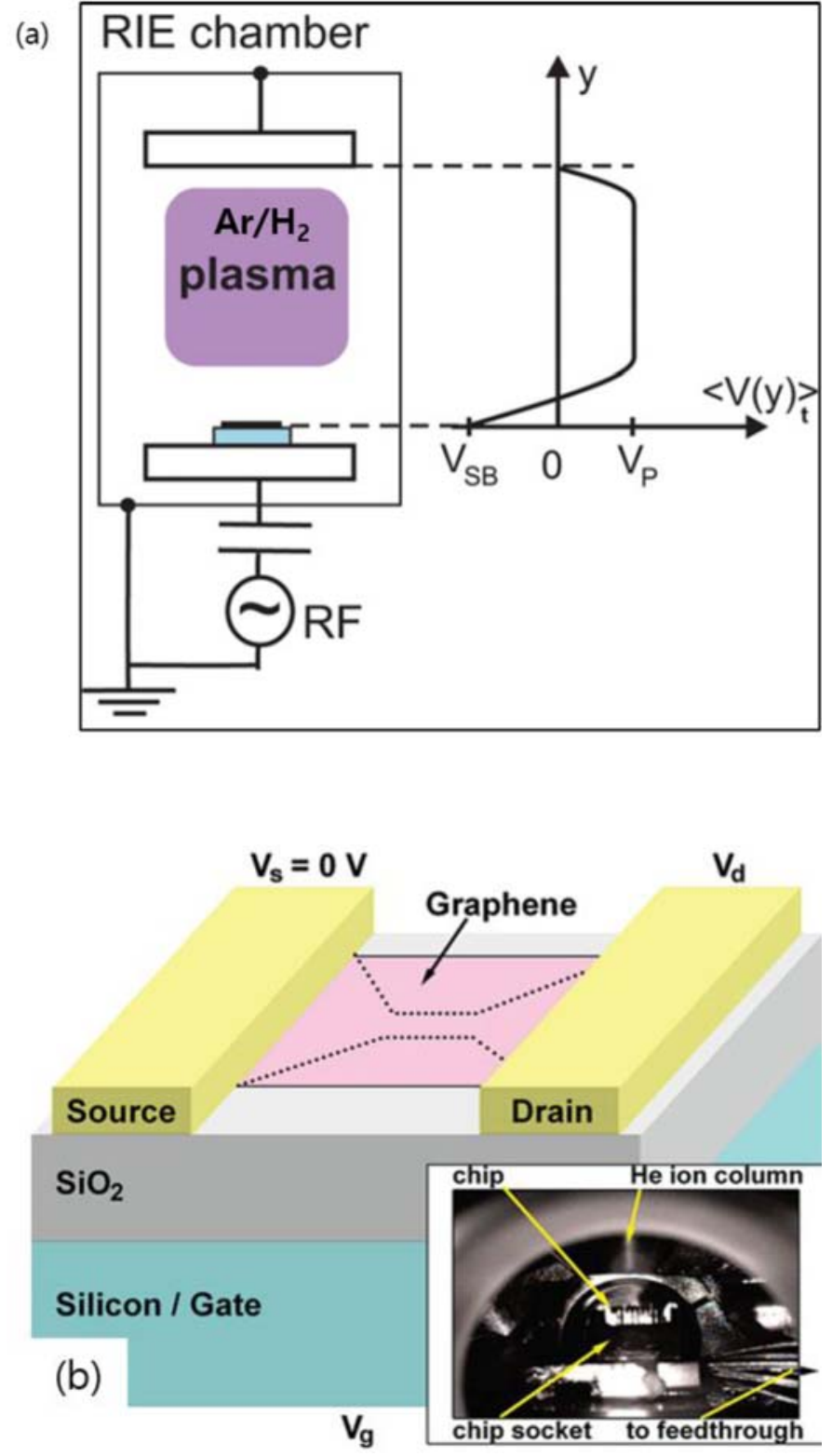


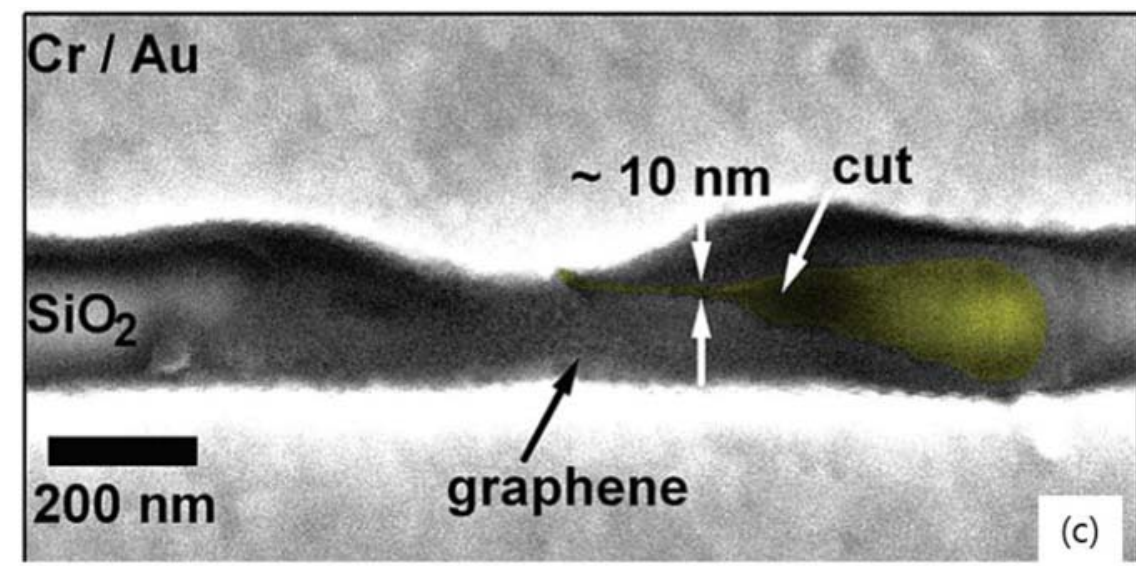

Figure 4. (a) Schematic of the reactive ion etching (RIE) system using $\mathrm{Ar} / \mathrm{H} 2$ mixture for etching of graphene/ $\mathrm{SiO}_{2}$. (b) Schematic of a graphene device. Inset: photograph of the microscope chamber with installed chip. (c) HeIM image (with false color) of a suspended graphene device after etching with minimum feature sizes of about $10 \mathrm{~nm}$. (a) is reproduced with permission from [25], copyright 2011, AIP Publishing. (b)-(c) are reproduced with permission from [26], copyright 2009, American Chemical Society. 

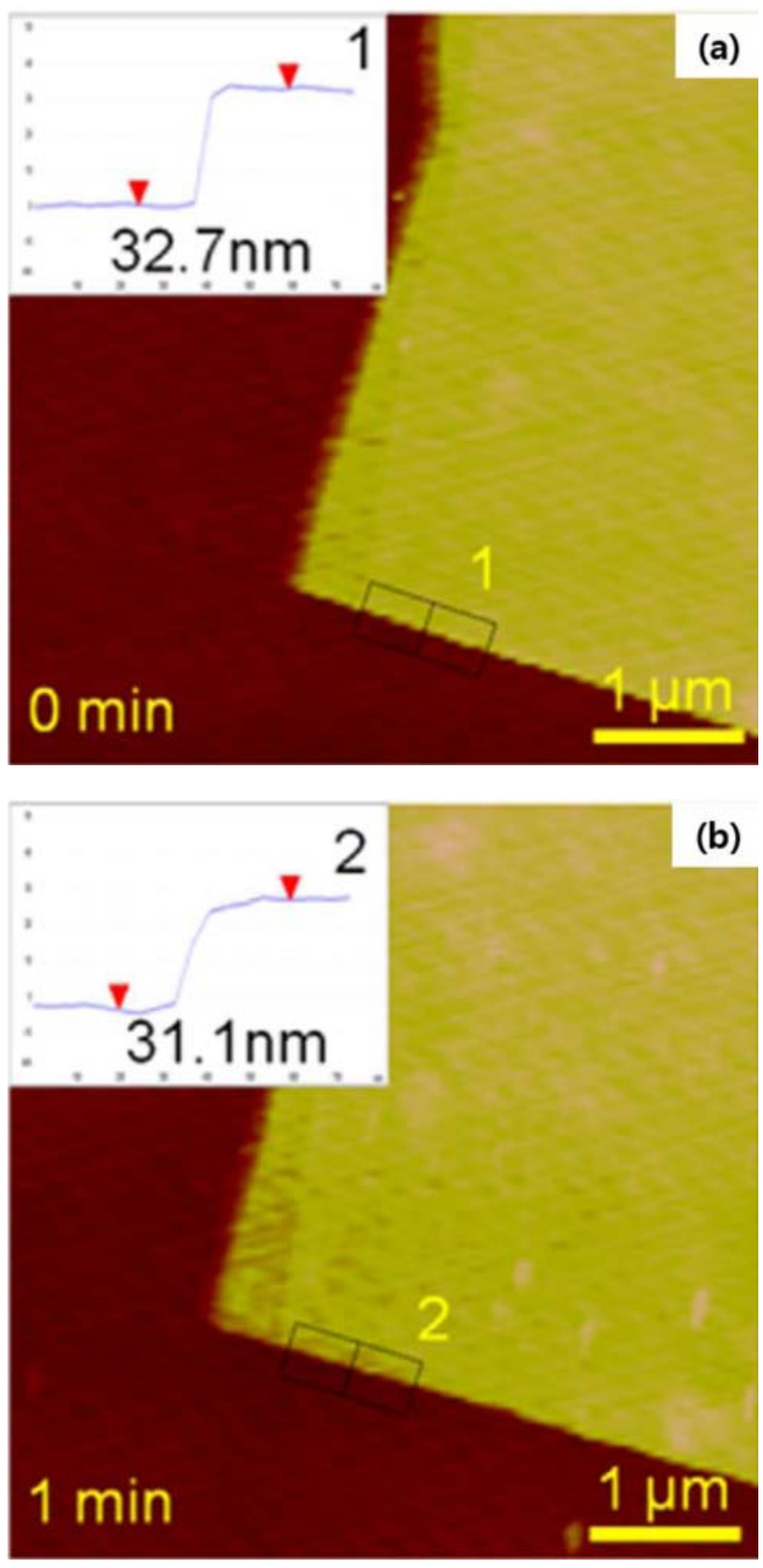

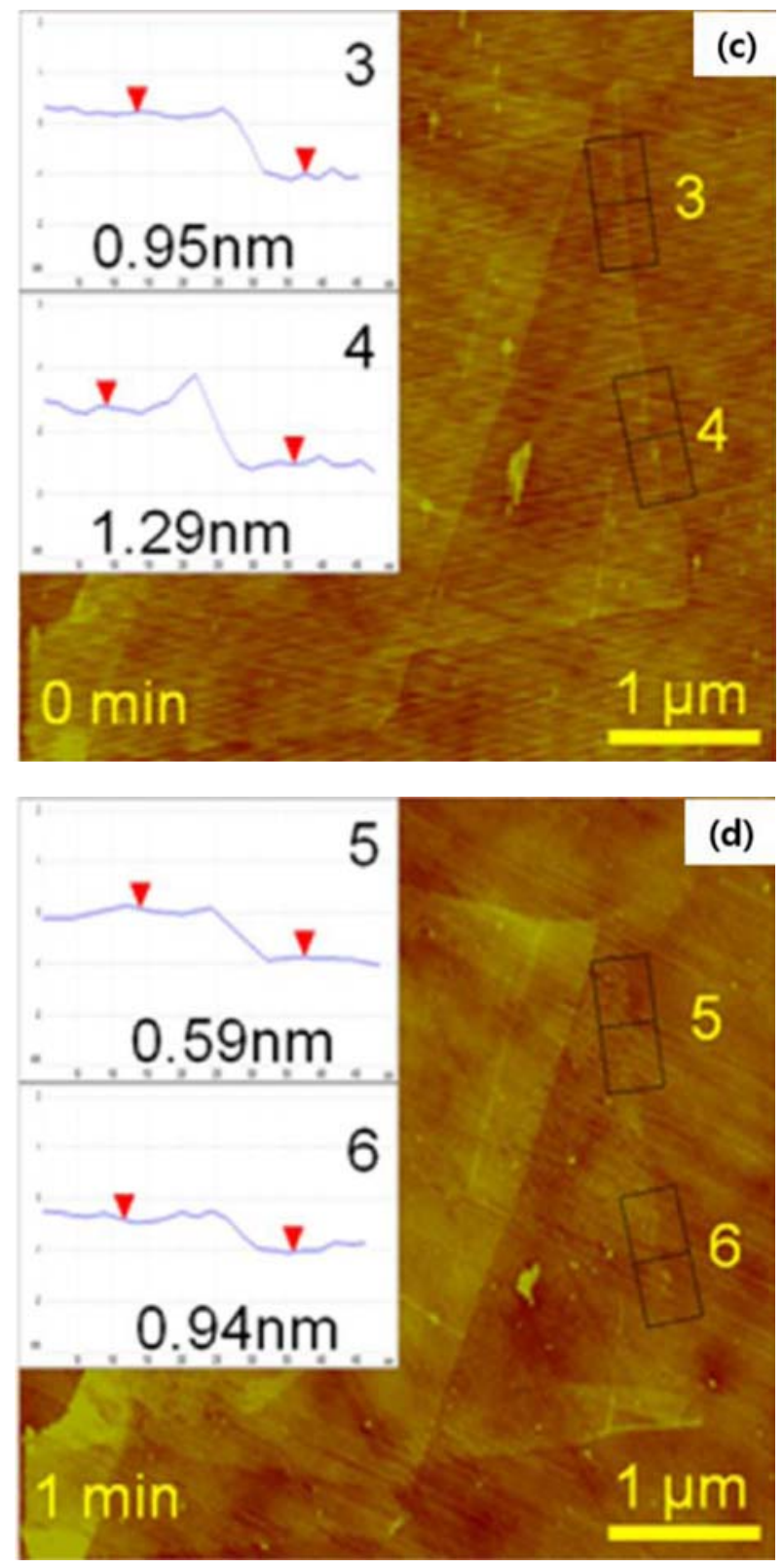

Figure 5. (a) Multilayer graphene before and (b) after He plasma exposure; (c) few-layer graphene before and (d) after He plasma exposure. (a)-(d) are reproduced with permission from [27], copyright 2012, IOP Publishing. 
For applications from the plasma-related graphene etching studies with various strategies and their related applications as summarized in Table 1. A chip device based on nanosphere-etched GNRs by low-power $\mathrm{O}_{2}$ plasma have carried out [21], and showed the superior electronic quality device as well as achieved the expected GNRs architectures (chains, branches, circular rings). Or a transistor has fabricated as a metal-oxide semiconductor (MOS), unfortunately, the etching effect of graphene was obtained but simultaneously the high energy plasma damage also occurred in resulting the poor electrical characteristics [23]. Or the fabrication of the monolayer-deep pattern based on the etched graphene by $\mathrm{N}_{2}$ plasma and annealing in $\mathrm{Ar} / \mathrm{O}_{2}$, Yang et al. showed its rather quality with a few defects [22]. Or for fabrication of FET device based on the thinned graphene sheet by He ion beam etching, as the result, the graphene sheet was as thin as $10 \mathrm{~nm}$ size [26]. 
Table 1. A summary of plasma-related graphene etching strategies and their related applications. Note that "NA" means "not applicable"

\begin{tabular}{|c|c|c|c|c|}
\hline Etching strategy & Substrate & $\begin{array}{l}\text { Applications of } \\
\text { etched-graphene }\end{array}$ & Results & Ref. \\
\hline $\begin{array}{l}\text { Nanosphere lithography using } \\
\text { low-power } \mathrm{O}_{2} \text { plasma etching }\end{array}$ & $\mathrm{SiO}_{2}$ & $\begin{array}{l}\text { Chip device based } \\
\text { on nanosphere- } \\
\text { shaped graphene } \\
\text { nanoribbons } \\
\text { (GNRs) }\end{array}$ & $\begin{array}{l}\text { Superior electronic } \\
\text { quality and achieved } \\
\text { GNRs architectures } \\
\text { included chains, } \\
\text { branches, circular } \\
\text { rings, and connected } \\
\text { rings at low cost }\end{array}$ & {$[21]$} \\
\hline $\mathrm{O}_{2}$ plasma etching & $\mathrm{SiC}$ & NA & NA & {$[20]$} \\
\hline $\mathrm{O}_{2}$ plasma etching by ICP-RIE & $\mathrm{SiO}_{2}$ & NA & NA & {$[19]$} \\
\hline $\begin{array}{c}\mathrm{N}_{2} \text { plasma }+ \text { Post annealing } \\
\left(\mathrm{Ar} / \mathrm{O}_{2}\right)\end{array}$ & $\mathrm{SiO}_{2}$ & $\begin{array}{l}\text { Monolayer-deep } \\
\text { patterns }\end{array}$ & $\begin{array}{l}\text { Thinned graphene } \\
\text { with good quality } \\
\text { with few defects }\end{array}$ & {$[22]$} \\
\hline $\begin{array}{c}\mathrm{O}_{2} \text { absorption }+ \text { Ar etching } \\
\text { by neutral beam }\end{array}$ & $\mathrm{SiO}_{2}$ & $\begin{array}{l}\text { Metal-oxide } \\
\text { semiconductor } \\
\text { (MOS) devices }\end{array}$ & $\begin{array}{l}\text { Poor electrical } \\
\text { characteristic due to } \\
\text { high energy damage }\end{array}$ & {$[23]$} \\
\hline $\begin{array}{c}\mathrm{O}_{2} \text { absorption }+ \text { Ar etching } \\
\text { by ion beam }\end{array}$ & $\mathrm{SiO}_{2}$ & NA & NA & {$[24]$} \\
\hline $\begin{array}{c}\text { Reactive ion etching (RIE) } \\
\text { system using } \mathrm{Ar} / \mathrm{H}_{2} \text { mixture }\end{array}$ & $\mathrm{SiO}_{2}$ & NA & NA & {$[25]$} \\
\hline $\begin{array}{c}\text { He ion beam lithography } \\
\text { etching }\end{array}$ & $\mathrm{SiO}_{2}$ & FET & $\begin{array}{c}\text { Suspended graphene } \\
\text { size about } 10 \mathrm{~nm}\end{array}$ & {$[26]$} \\
\hline Low energy He plasma etching & $\mathrm{SiO}_{2}$ & NA & NA & {$[27]$} \\
\hline
\end{tabular}

\section{Conclusion}

In general, there are still many unexploited huge potentials from the etched graphene products. But, the perspectives on that would be bright, in addition, if these etching methodologies are applied to the other lowdimensional materials such as transition metal dichalcogenides (TMDs) or transition metal carbides, nitrides, and carbonitrides (MXenes). Surely that, it could unlock a new chapter in many further high-quality electronics and optoelectronics. The increasing the controlled bandgap of 
2D materials would be raising up the current on-off ratio, photoluminescence, and other unexploited and unexplored exotic properties. Especially, the layer-by-layer etching of 2D materials by lowenergy plasma (low-damage, neutral beam, ion beam) without inducing the physical and chemical damage has successfully demonstrated in 2017 [24].

\section{References}

[1] K. S. Novoselov, A. K. Geim, S. V. Morozov, D. Jiang, Y. Zhang, S. V. Dubonos, I. V. Grigorieva and A. A. Firsov, Electric field effect in atomically thin carbon films, Science 306(5696) (2004), 666-669.

DOI: http://dx.doi.org/10.1126/science.1102896

[2] V. P. Pham, H. S. Jang, D. Whang and J. Y. Choi, Direct growth of graphene on rigid and flexible substrates: Progress, applications, and challenges, Chem. Soc. Rev. 46(20) (2017), 6276-6300.

DOI: http://dx.doi.org/10.1039/c7cs00224f

[3] V. P. Pham, M. T. Nguyen, J. W. Park, S. S. Kwak, D. H. T. Nguyen, M. K. Mun, H. D. Phan, D. S. Kim, K. H. Kim, J. Lee, N. E. Lee and G. Y. Yeom, Chlorinetrapped CVD bilayer graphene for resistive pressure sensor with high detection limit and high sensitivity, 2D Materials 4(2) (2017), Article 025049.

DOI: https://doi.org/10.1088/2053-1583/aa6390

[4] V. P. Pham, K. N. Kim, M. H. Jeon, K. S. Kim and G. Y. Yeom, Cyclic chlorine trapdoping for transparent, conductive, thermally stable and damage-free graphene, Nanoscale 6(24) (2014), 15301-15308.

DOI: http://dx.doi.org/10.1039/c4nr04387a

[5] V. P. Pham, K. H. Kim, M. H. Jeon, S. H. Lee, K. N. Kim and G. Y. Yeom, Low damage pre-doping on CVD graphene/Cu using a chlorine inductively coupled plasma, Carbon 95 (2015), 664-671.

DOI: https://doi.org/10.1016/j.carbon.2015.08.070

[6] V. P. Pham, A. Mishra and G. Y. Yeom, The enhancement of hall mobility and conductivity of CVD graphene through radical doping and vacuum annealing, RSC Adv. 7(26) (2017), 16104-16108.

DOI: http://dx.doi.org/10.1039/c7ra01330b

[7] V. P. Pham, D. S. Kim, K. S. Kim, J. W. Park, K. C. Yang, S. H. Lee, G. Y. Yeom and K. N. Kim, Low energy $\mathrm{BCl}_{3}$ plasma doping of few-layer graphene, Sci. Adv. Mater. 8(4) (2016), 884-890.

DOI: https://doi.org/10.1166/sam.2016.2549 
[8] K. N. Kim, V. P. Pham and G. Y. Yeom, Chlorine radical doping of a few layer graphene with low damage, ECS J. Solid State Sci. Technol. 4(6) (2015), N5095-N5097.

$$
\text { DOI: http://dx.doi.org/10.1149/2.0141506jss }
$$

[9] V. P. Pham, Chemical vapor deposited graphene synthesis with same-oriented hexagonal domains, Eng. Press 1(2) (2018), 39-42.

DOI: $10.28964 /$ EngPress-1-107

[10] V. P. Pham, How can the nanomaterial surfaces be highly cleaned?, Edelweiss Appl. Sci. Tech. 2(1) (2018), 184-186.

[11] V. P. Pham, Layer-by-layer thinning of 2D materials, Edelweiss Appl. Sci. Tech. 2(1) (2018), 36-37.

[12] V. P. Pham, Cleaning of graphene surface by low-pressure air plasma, Royal Society Open Science 5 (2018), Article 172395.

DOI: http://dx.doi.org/10.1098/rsos.172395

[13] H. Tomas, P. Jan, K. Richard, S. Pavel, D. Petr, W. Martin and C. Mirko, Atmospheric dry hydrogen plasma reduction of inkjet-printed flexible graphene oxide electrodes, ChemSusChem 11(5) (2018), 941-947.

DOI: http://dx.doi.org/10.1002/cssc.201702139

[14] A. C. Ferrari, F. Bonaccorso, V. Fal'ko et al., Science and technology roadmap for graphene, related two-dimensional crystals, and hybrid systems, Nanoscale 7(11) (2015), 4598-4810.

DOI: http://dx.doi.org/10.1039/c4nr01600a

[15] S. Z. Butler, S. M. Hollen, L. Cao, Yi Cui, J. A. Gupta, H. R. Guitierrez, T. F. Heinz, S. S. Hong, J. Huang, A. F. Ismach, E. J. Halperin, M. Kuno, V. V. Plashnitsa, R. D. Robinson, R. S. Rouff, S. Salahuddin, J. Shan, L. Shi, M. G. Spencer, M. Terrones, W. Windl and J. E. Goldberger, Progress, challenges, and opportunities in two-dimensional materials beyond graphene, ACS Nano 7(4) (2013), 2898-2926.

DOI: http://dx.doi.org/10.1021/nn400280c

[16] A. K. Geim and K. S. Novoselov, The rise of graphene, Nat. Mater. 6 (2007), 183-191.

DOI: http://dx.doi.org/10.1038/nmat1849

[17] H. Zhang, P. Yang and M. Prato, Grand challenges for nanoscience and nanotechnology, ACS Nano 9(7) (2015), 6637-6640.

DOI: http://dx.doi.org/10.1021/acsnano.5b04386

[18] V. M. Donnelly and A. Kornblit, Plasma etching: Yesterday, today, and tomorrow, J. Vac. Sci. Tech. A 31(5) (2013), Article 050825.

DOI: https://doi.org/10.1116/1.4819316 
[19] H. Al-Mumen, F. Rao, W. Li and L. Dong, Singular sheet etching of graphene with oxygen plasma, Nano-Micro Lett. 6(2) (2014), 116-124.

DOI: http://dx.doi.org/10.5101/nml.v6i2.p116-124

[20] Y. J. Shin, Y. Wang, H. Huang, G. Kalon, A. T. S. Wee, Z. Shen, C. S. Bhatia and H. Yang, Surface-energy engineering of graphene, Langmuir 26(6) (2010), 3798-3802.

DOI: http://dx.doi.org/10.1021/la100231u

[21] L. Liu, Y. Zhang, W. Wang, C. Gu, X. Bai and E. Wang, Nanosphere lithography for the fabrication of ultranarrow graphene nanoribbon and on-chip bandgap tuning of graphene, Adv. Mater. 23(10) (2011), 1246-1251.

DOI: https://doi.org/10.1002/adma.201003847

[22] X. Yang, S. Tang, G. Ding, X. Xie, M. Jiang and F. Huang, Layer-by-layer thinning of graphene by plasma irradiation and post-annealing, Nanotechnology 23(2) (2011), Article 025704.

DOI: http://dx.doi.org/10.1088/0957-4484/23/2/025704

[23] W. S. Lim, Y. Y. Kim, H. Kim, S. Jang, N. Kwon, B. J. Park, J. H. Ahn, I. Chung, B. H. Hong and G. Y. Yeom, Atomic layer etching of graphene for full graphene device fabrication, Carbon 50(2) (2011), 429-435.

$$
\text { DOI: https://doi.org/10.1016/j.carbon.2011.08.058 }
$$

[24] K. S. Kim, Y. J. Ji, Y. Nam, K. H. Kim, E. Singh, J. Y. Lee and G. Y. Yeom, Atomic layer etching of graphene through controlled ion beam for graphene-based electronics, Sci. Rep. 7 (2017), Article 2462.

DOI: http://dx.doi.org/10.1038/s41598-017-02430-8

[25] M. Wojtasszek, N. Tombros, A. Caretta, P. H. M. V. Loosdrecht and B. J. V. Wees, A road hydrogenating graphene by a reactive ion etching plasma, J. Appl. Phys. 110(6) (2011), Article 063715.

DOI: https://doi.org/10.1063/1.3638696

[26] M. C. Lemme, D. C. Bell, J. R. Williams, L. A. Stern, B. W. H. Baugher, P. J. Herrero and C. M. Marcus, Etching of graphene devices with a helium ion beam, ACS Nano 3(9) (2009), 2674-2676.

DOI: http://dx.doi.org/10.1021/nn900744z

[27] W. Luo, J. Xie, C. Li, Y. Zhang and Y. Xia, High-precision thickness regulation of graphene layers with low energy helium plasma implantation, Nanotechnology 23(37) (2012), Article 375303.

DOI: https://doi.org/10.1088/0957-4484/23/37/375303 